\title{
The RAMNI airborne lidar for cloud and aerosol research
}

\author{
F. Cairo ${ }^{1}$, G. Di Donfrancesco ${ }^{2}$, L. Di Liberto ${ }^{1}$, and M. Viterbini ${ }^{1}$ \\ ${ }^{1}$ Istituto di Scienze dell' Atmosfera e del Clima, Consiglio Nazionale delle Ricerche, Roma, Italy \\ ${ }^{2}$ Ente Nazionale per le Nuove tecnologie, l'Energia e l'Ambiente, Roma, Italy \\ Correspondence to: F. Cairo (f.cairo@isac.cnr.it)
}

Received: 30 December 2011 - Published in Atmos. Meas. Tech. Discuss.: 9 February 2012

Revised: 29 May 2012 - Accepted: 12 June 2012 - Published: 25 July 2012

\begin{abstract}
We describe an airborne lidar for the characterization of atmospheric aerosol. The system has been set up in response to the need to monitor extended regions where the air traffic may be posed at risk by the presence of potentially harmful volcanic ash, and to study the characteristics of volcanic emissions both near the source region and when transported over large distances. The lidar provides backscatter and linear depolarization profiles at $532 \mathrm{~nm}$, from which aerosol and cloud properties can be derived. The paper presents the characteristics and capabilities of the lidar system and gives examples of its airborne deployment. Observations from three flights, aimed at assessing the system capabilities in unperturbed atmospheric conditions, and at characterizing the emissions near a volcanic ash source (Mt. Etna) and transported far away from the source, are presented and discussed.
\end{abstract}

\section{Introduction}

The lidar technique has high potentials for assessing the particulate burden of the atmosphere, since it is currently the only remote sensing system that allows the direct determination of the vertical profiles of optical properties of micronsized aerosols, and particles in thin clouds. Due to new powerful laser sources and improved electronics, profiles of the optical properties of the atmosphere can be achieved with high spatial and temporal resolution, typically of the order of meters, and of seconds. Such high resolution allows both to monitor the temporal evolution of the stratification and dynamics of aerosols in the atmosphere above a ground-based station, and to sample extended regions, when the instrument is mounted on moving platforms such as vans, ships or aircraft (Lilley et al., 2004). Airborne lidars have been used since the early eighties (Moerl et al., 1981; Browell et al., 1990; Renger et al., 1997; Flamant et al., 2000; McGill et al., 2002) and now reliable, robust, transportable systems are widely used throughout the world, deployed in remote sites in harsh conditions, on board of both large (Stachlewska et al., 2010) or ultralight (Chazette et al., 2007) aircraft. The capability of airborne lidar to measure the atmospheric particulate in real time over extended regions, has demonstrated its great usefulness in response to the recent emergency, induced by the Eyjafjalla volcano eruption between April and May 2010 (Petersen, 2010). Then, the volcanic plume originated from the eruption, dwelled over Europe for several weeks, hampering the civil air traffic and perturbing the economic, political and cultural activities of the continent. Consequently, several airborne lidar usually devoted to atmospheric research were deployed to perform measurements of aerosols and volcanic ashes (Schumann et al., 2011; Marenco et al., 2011). That effort of the scientific community toward monitoring and quantifying the presence of ash had the twofold goal both to study the evolution and fate of the volcanic plume (Bukowiecki et al., 2011; Ansmann et al., 2011; Wiegner et al., 2011), and to provide input to decision makers that had to face such civil contingency.

Lidar can easily detect the presence of volcanic ash, identified by using polarization diversity and/or multi-wavelength backscatter systems (Wiegner et al., 2011). The amount of ash can then be assessed under some assumption on particle size spectrum, refractive index and density (Ansmann et al., 2010; Gasteiger et al., 2011). Such information, provided in real time, allowed for the validation of the reports and forecasts of the volcanic ash cloud transport, issued by the Volcanic Ash Advisory Centers, and to inform the national Civil Aviation Authorities that had to issue warnings for the flight safety over extended areas, possibly affected by ash presence. 
Triggered by the need to provide adequate coverage to the national territory, in May 2010 the Italian civil aviation authority asked our Institution to set up an airborne lidar capable to detect and quantify the presence of particulate and ashes in the atmosphere. A lidar (RAMNI - Radar ottico Aviotrasportato per il Monitoraggio delle No-flight zones sopra Italia - Airborne Optical radar for monitoring No-Flight Zones over Italy) has then been certified to fly, installed and tested on an Alenia C-27J Spartan, a medium-sized transport aircraft of the Italian Air Force. Such system is now operative and obeys the twofold role of providing the atmospheric science community with a research instrument tested for airborne operations, and to deliver operatively real-time estimates of the volcanic ash burden in the atmosphere, in case of civil contingencies. The present work describes the characteristics of the RAMNI system and the data analysis procedure, and illustrates some of its observations. Results from flights aimed at testing the capabilities of the system and at detecting the presence of ashes emitted from Mt. Etna and from Grimsvötn volcanoes are here presented and discussed.

\section{Instrument description}

The RAMNI lidar that has been installed on the C-27J, belongs to the instrumental equipment usually present in the experimental facility of San Pietro Capofiume $\left(11.6^{\circ} \mathrm{E}\right.$, $44.7^{\circ} \mathrm{N}$ ), maintained by the Institute of Atmospheric Sciences and Climate of the Italian National Research Council. It was designed and implemented in the framework of a collaboration between ISAC-CNR, the Ente Nazionale per le Nuove tecnologie, l'Energia e l'Ambiente (ENEA) and Embedded Devices s.r.l. (now IsoComp, www.isocomp.it), an Italian SME. Systems sharing some common feature with the one hereby described have been used in remote sites in Africa (Cavalieri et al., 2011, 2010) and Spitzbergen (Svalbard) (Di Liberto et al., 2012). The system, designed for unattended outdoor use and whose total weight is $30 \mathrm{~kg}$, is contained in a $30 \times 40 \times 50 \mathrm{~cm}$ aluminum box, electronically shielded and thermally insulated with polyurethane. A quartz window allows the transmission of the laser pulse toward the atmosphere, and the collection of the backscattered signal. The temperature in the aluminum box is controlled by four cooler-heater Peltier cells, 20W each, which maintain the temperature within the laser operating conditions $\left(10^{\circ} \mathrm{C}-\right.$ $\left.30^{\circ} \mathrm{C}\right)$. The system power consumption is less than $240 \mathrm{~W}$ $(10 \mathrm{~A}$ at $24 \mathrm{~V})$.

\subsection{Transmitter}

The laser source (Bright Solutions, Wedge) is an air cooled, diode pumped Nd-YAG, with second-harmonic generation and active $\mathrm{Q}$ switching. The laser pulse duration is $1 \mathrm{~ns}$ and the emission is on two wavelengths, with energies of $350 \mu \mathrm{J} /$ pulse at $532 \mathrm{~nm}$ (green) and $800 \mu \mathrm{J} /$ pulse at $1064 \mathrm{~nm}$ (near infrared). The pulse repetition rate is $1 \mathrm{kHz}$. From factory specifications, the laser beam divergence is $3 \mathrm{mrad}$ and is further reduced by a factor of 7 by a beam expander. The half divergence (sdiv) of the laser has been measured by following horizontally in an open field the diverging beam cross section, for a distance of $350 \mathrm{~m}$. The beam cross section resulted to be elliptical, and its divergence was different along the two main axes. The measured minimum value of the two half divergences was sdiv $=0.2 \mathrm{mrad}$. This leads to a decrease of the energy density $S(r)$ across the beam section with the distance $r$ from the source, that decreases more rapidly than

$S(r)=\frac{E}{r^{2} \cdot \operatorname{sdiv}}$

where $E$ is the pulse energy. This equation allowed us to define the minimum safety distance beyond which the laser beam is considered eye safe. Eye safety is a major concern for both nadir or zenith pointing airborne lidars, and is further discussed and detailed in Appendix A. The laser beam is sent into the atmosphere by means of a steerable dielectric mirror, placed before the beam expander. The mirror positioner allows fine alignments of the beam with respect to the telescope field of view (FOV).

\subsection{Receiver}

The optical receiver is a Newtonian telescope with a diameter of $20 \mathrm{~cm}, f / 1.5$, with a FOV of $0.75 \mathrm{mrad}$, regulated by a pinhole of $200 \mu \mathrm{m}$ placed in the telescope focal plane, acting as field stop. Under this geometry, the overlap of the laser beam with the telescope FOV begins at $40 \mathrm{~m}$ from the instrument and is completed at $600 \mathrm{~m}$.

A gray photochromic glass is placed in the telescope focal plane. The glass darkens on exposure to ultraviolet (UV) radiation, and gradually returns clear when UV is removed, on a timescale of some minutes. The system efficiency then decrease by a factor of 4 , under conditions of strong sky background light, i.e. when used in daylight, while maximum sensitivity is achieved during nighttime; this allows to moderate the effects of saturation and non linearity on the light detectors under strong light exposure. The photochromic glass response to fast background light changes - as those that may occur when white clouds cross the telescope FOV - is considered slow enough to deem the glass attenuation constant over the time a single lidar profile is averaged. After the telescope focal plane the light is collimated by a $2 \mathrm{~cm}$ diameter, $f / 1.5$ achromatic lens. Two low-pass dichroic cubes act to split the radiation into different paths according to its wavelength. Narrow band interference filters with $2 \mathrm{~nm}$ bandwidth (Semrock) are placed on each of the different paths to separate the backscatter at $532 \mathrm{~nm}$, at $608 \mathrm{~nm}$ - the Raman scattering from Nitrogen - and $1064 \mathrm{~nm}$. These filters have high transmission $(\geq 90 \%)$ and a negligible temperature dependence. A cube polarizer is used to further divide the radiation at $532 \mathrm{~nm}$ in the components parallel and perpendicular to the plane of 
polarization of the emitted light. The radiation at 608 and $532 \mathrm{~nm}$ is directed on miniature photomultiplier modules (Hamamatsu 5783P and 6780-20, respectively) with very low thermal noise (less than 10 counts/s at $25^{\circ} \mathrm{C}$ ). The $1064 \mathrm{~nm}$ radiation is focused, by a steerable small parabolic mirror, into an Avalanche Photo Diode (APD) C30954E (EGG) with $0.8 \mathrm{~mm}$ photo sensitive area diameter. The polarization voltage for the APD is set manually to a suitable value by a custom electronic board. These electronics allows to keep the APD gain fixed, by automatically varying the polarization voltage and hooking it to possible APD temperature changes, in accordance with the APD gain vs. temperature curve.

\subsection{Data acquisition}

The photodetector signal is amplified with a gain of 11 and a bandwidth of $250 \mathrm{MHz}$. As usual in photomultiplier detection, two cases arises: if the photon arrival rate is such that the electrical impulses, originated by the single photon detection process, pile up to produce a continuous current waveform, the signal is measured in current mode; if otherwise the photon arrival rate is low enough to allow to discriminate the single photon electrical impulses, the signal is measured in photoncounting mode. In our case, the signal is simultaneously recorded both in current and in photocounting mode, and the two acquisitions are then suitably merged when the data are processed, as detailed hereafter. The electronic acquisition card (Embedded Devices, APC-80250DSP) is based on FPGA technology and uses a fast digital signal processor unit (DSP) for both modes. In current mode, the photomultiplier signal is filtered through a $15 \mathrm{MHz}$ low pass to avoid aliasing effects, and then digitized into an 8 bits waveform, at an adjustable sampling rate. The duration of the single sample can be set to $12.5,25,50$ or $100 \mathrm{~ns}$, and the waveform is reconstructed for a total of 1024 samples. The number of samples is fixed - the first 24 collected before the laser shot and used for measuring background light. This renders a spatial resolution spanning from $1.875 \mathrm{~m}$ to $15 \mathrm{~m}$. Accordingly, the total sampled waveform duration corresponds to spatial range that can vary from 1.875 to $15 \mathrm{~km}$.

In photoncounting mode the impulses originating from photon detection are counted when they reach an adjustable threshold level that allows the rejection of spurious low noise. For each photon detection, TTL pulses are formed and counted in 1024 consecutive time bins, whose length may span from 25 to $1000 \mathrm{~ns}$ in $25 \mathrm{~ns}$ increments, rendering a spatial resolution along the lidar profile that can be set from $3.75 \mathrm{~m}$ to $150 \mathrm{~m}$. Since the first 24 are collected before the laser shot and used for measuring background light, the overall profile range can vary from 3.75 to $150 \mathrm{~km}$.

The acquisition card provides the sum of the signals integrated over $N$ laser shots. Thus, profiles are produced as averages over times that can range from $1 \mathrm{~s}$ (i.e. a minimum of 1000 laser shots, whereas the frequency of laser pulses is $1 \mathrm{kHz}$ ) to possibly several tens of hours, and the averaging
Table 1. Synopsis of the system specifications.

\begin{tabular}{ll}
\hline \multicolumn{2}{c}{ Technical specifications of the RAMNI system } \\
\hline Detected wavelengths & 1064,608 and $532 \mathrm{~nm}$ (two polarizations) \\
Laser type & Nd-YAG $(1064$ and $532 \mathrm{~nm})$ \\
Pulse duration & $1 \mathrm{~ns}$ \\
Laser repetition rate & up to $-1 \mathrm{kHz}$ \\
Laser output energy & $0.8 \mathrm{~mJ}$ at $1064 \mathrm{~nm} ; 0.35 \mathrm{~mJ}$ at $532 \mathrm{~nm}$ \\
Telescope diameter & $20 \mathrm{~cm}$ \\
Telescope type & F/1.5 Newtonian \\
Telescope field of view & $0.7 \mathrm{mrad}$ \\
Beam divergence & $0.4 \mathrm{mrad}$, full angle \\
Filter bandwidth & $2 \mathrm{~nm}$ \\
Vertical resolution & From 3.75 to $150 \mathrm{~m}$ in photoncounting mode \\
& From 1.875 to $15 \mathrm{~m}$ in current mode \\
Vertical range & $1024 \times$ Vertical resolution \\
Time resolution & down to $1 \mathrm{~s}$ \\
\hline
\end{tabular}

time can be adjusted by means of the control software. A good compromise between good signal to noise ratio and a sufficient temporal resolution is generally obtained by setting the time average between 5 and $60 \mathrm{~s}$. Averaged profiles are stored in the memory board of the system (expandable to several GB), which can accumulate tens of thousands of them. An external computer is used to access the system and a dedicated software package allows to modify the settings of the acquisition card (average profile duration, its vertical extension and resolution, frequency and power of the laser pulse, photoncounting threshold level and so on) via USB or TCP/IP connection. The system automatically starts operating and storing data as it gets turned on, and stops when it is turned off, or whenever an appropriate command is sent from an external computer, as when it is necessary to stop the data logging to download the data or to provide real-time data visualization for alignment purposes. Data are stored as ASCII files. Each file reports information on the system settings, housekeeping data (temperatures in some critical parts, voltage levels, ambient pressure) and the raw data as a series of photocounts per bin, and averaged current waveforms in digit units. A real time visualization of the measurements is possible on an external computer by means of a suitable software package, for system checking or for alignment. A synopsis of the system specifications is reported in Table 1 . The photoncounting mode, preferable in the acquisition of atmospheric returns from distant ranges due to better signal to noise ratio and absence of spurious electronic biases, tends to get saturated in bright daylight, for the acquisition of atmospheric returns from regions close to the instrument. In these conditions, use of the current mode is mandatory. A vertical region of overlap between current and photoncounting mode acquisitions exists, and allows merging the two to reconstruct the whole backscattering profile from a few tens of meters from the instrument to the maximum altitude of the sounding. The region where the two acquisition modes coexist and are both accurate and sensitive, is placed generally between $2 \mathrm{~km}$ and 
the top of the current mode profile, which can be at $3.75 \mathrm{~km}$ or higher. In this region, the photoncounting mode has still a good linearity and current mode is sensitive enough.

\subsection{Electromagnetic and mechanical compatibility}

The system was tested at the Laboratory for Electromagnetic Fields ENEA Casaccia, in order to characterize the emissions radiated and conducted, to check the compatibility of its use on an airplane. The tests were conducted in more sessions in the period from June to July and November 2010. At the end of the test series, it has been certified (Test Report ENEA EMFLab04/2010 EMFLab and 05/2010) that the lidar system emits conducted and radiated noise levels below the limits prescribed by the relevant legislation. Therefore, it meet the requirements of MIL-STD 461E CE102 and RE102 for the tests.

\section{Data processing}

The system is able to measure the atmospheric return backscattered elastically at $1064 \mathrm{~nm}$, at $532 \mathrm{~nm}$ in parallel and perpendicular polarization, and the nitrogen Raman scattered signal at $608 \mathrm{~nm}$; although this latter is available only at night due to the low value of its scattering cross section. Unfortunately, for the measurements acquired during the flights presented hereafter, the $1064 \mathrm{~nm}$ data were plagued by a spurious noise that hampered their use in a quantitative way. We will present and quantitatively discuss here only the data acquired with the polarization diversity $532 \mathrm{~nm}$ channels.

The data processing is not automated but done by an operator after the end of each measurement session, with an originally implemented software code. Quality checked data can be delivered after one hour from the measurement. The preliminary step in the data processing procedure is the correction for dead time effects on the photoncounting mode profiles. According to Donovan et al. (1993), let $S_{0}$ the true photocounting rate, and $S_{v}$ the photocounting rate observed by our device; the two are linked by

$S_{v}=S_{0} \cdot \exp \left(-S_{0} \cdot \tau\right)$

where the dead time $\tau$ can be estimated from the maximum observed photocounting rate as $\tau=\frac{1}{R_{v}^{\max } \cdot e}$ and in our case is $6 \mathrm{~ns}$. Equation (2) allows the retrieval of the true photoncounting rate, and this extends some hundreds of meters down the limit where the photoncounting profile can be considered accurate. The part of the photoncounting profile further down, generally below $1 \mathrm{~km}$ in daylight, or even further down at nighttime where the correction would exceeds $50 \%$, is considered not reliable.

The current mode profile is corrected for the partial overlap between the laser beam and the FOV in the near range, so that the signal in the near range is reconstructed using the procedure described in Biavati et al. (2011). The correction is considered reliable if it does not exceed $75 \%$ of the reconstructed signal. In this way, an atmospheric profile is retrieved down to $100-200 \mathrm{~m}$ from the instrument. The current and photoncounting profiles are then superimposed and merged together in a region where both acquisition modes are considered sensitive and accurate. This region may vary according to the background light level and to the amount and distribution of aerosol. Generally, we prefer the photoncounting acquisition as it is known to be superior to the current one in terms of stability, detection efficiency, and signal to noise ratio (Tull , 1968), and is less affected by nonlinearities arising from the extensive dynamical range of the atmospheric backscatter signal (Cairo et al., 1996). Therefore, the current acquisition is used only when the photocounting starts showing saturation effects, i.e. when the photoncounting rate exceeds $10 \mathrm{MHz}$. Henceforth, for the polarized channel, current mode is used generally below $2-4 \mathrm{~km}$ in daylight, and below $1-2 \mathrm{~km}$ during nighttime. The merging delivers a single atmospheric profile for each polarization, with data below the merging region acquired in current mode and data above that in photocounting mode. Figure 1 displays the atmospheric elastic, polarization preserving, backscatter signal acquired on a clear night with $300 \mathrm{~s}$ integration time. The figure reports the atmospheric return as photoncounting rates per single laser shot, for the photoncounting mode acquisition, and in analog to digital converter digit units, ranging from 0 to 255 , for the current mode acquisition. The photocounting mode acquisition is presented before (black line) and after (blue line) the application of the dead time correction the current mode acquisition is displayed before (red line) and after (purple line) the application of the partial overlap correction. Also displayed are the altitude regions where the overlapping photoncounting and current signals are merged. The inelastic nitrogen Raman signal, acquired with $1500 \mathrm{~s}$ integration time (green solid line), is also displayed. The Raman signal is acquired in photoncounting mode only.

\subsection{Uncertainty analysis}

We discuss the uncertainty to be attributed to the retrieval of the physical quantities of interest, namely the aerosol backscattering coefficient and depolarization, following the well established literature on the lidar error analysis (Russell et al., 1979), which we will briefly summarize. We will use the result hereby discussed to calculate the uncertainty on our measurements, and from these considerations we will estimate the minimum aerosol signal detectable with sufficient accuracy, when presenting the measurement from one of the flights, in Sect. 4.

\subsubsection{Aerosol backscatter coefficient}

Let $N(r)$ be the number of photons generated by the process of backscatter at a distance $r$ from the system and detected by our lidar system, in case of photoncounting detection, or a current directly proportional to them in case of 


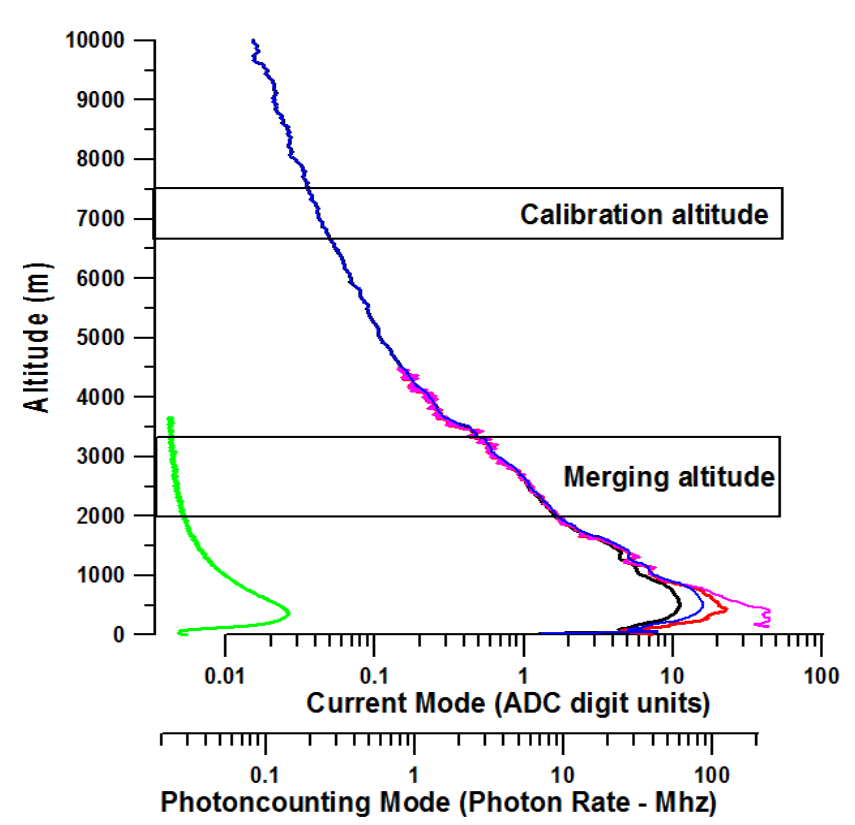

Fig. 1. Atmospheric elastic (300 s average) and Raman (1500 s average) backscatter return. Photon counting acquisition for the elastic backscattering, before (black) and after (blue) dead time correction. Current acquisition for the elastic backscattering, before (red) and after (purple) partial overlap correction. The green solid line reports the Raman backscattering acquired in photoncounting mode. The data were acquired on 7 December at 20:20 LT, and represent (photoncounting) or are proportional to (current) the photon flux induced by a single laser shot.

current detection; let $E$ the energy of the laser pulse, $C$ a parameter that describes the overall efficiency of the system, $\beta(r)$ and $\alpha(r)$, respectively, the backscatter coefficient and atmospheric extinction. We start from the well known lidar equation:

$$
\begin{aligned}
N(r) & =\frac{E \cdot C \cdot \beta(r)}{r^{2}} \cdot \exp \left(-2 \cdot \int_{0}^{r} \alpha(r) \mathrm{d} r\right) \\
& =\frac{E \cdot C \cdot \beta(r)}{r^{2}} \cdot T(r),
\end{aligned}
$$

where the term $T(r)$ expresses the atmospheric transmission from the lidar to the scattering region at distance $r$ and back, and it is understood that in the case of elastic scattering, extinction and backscatter coefficients can be divided into a contribution due to air molecules and aerosol:

$\beta(r)=\beta_{\mathrm{m}}(r)+\beta_{\mathrm{a}}(r)$

$\alpha(r)=\alpha_{\mathrm{m}}(r)+\alpha_{\mathrm{a}}(r)$.

A quantity commonly used in lidar research is the total Backscatter Ratio $R$

$R(r)=\frac{\beta(r)}{\beta_{\mathrm{m}}(r)}$ defined so that $R=1$ if there are no aerosols, and $R \geq 1$ otherwise. This is rewritten in terms of measured quantities as

$R(r)=\frac{N(r) \cdot r^{2}}{E \cdot C \cdot \beta_{\mathrm{m}}(r) \cdot T(r)}$.

The system parameters $E$ and $C$ are eliminated by a calibration procedure that assumes as known the value $R_{0}=R\left(r_{0}\right)$ at a given calibration altitude $r_{0}$. Then

$R(r)=\frac{R_{0} \cdot N(r) \cdot r^{2} \cdot \beta_{\mathrm{m}}\left(r_{0}\right) \cdot T\left(r_{0}\right)}{N\left(r_{0}\right) \cdot r_{0}^{2} \cdot \beta_{\mathrm{m}}(r) \cdot T(r)}$

and once $R(r)$ is retrieved from the measurements, we finally get to the quantity of physical interest, the aerosol volume backscatter coefficient:

$\beta_{\mathrm{a}}(r)=(R(r)-1) \cdot \beta_{\mathrm{m}}(r)$.

Introducing the dimensionless parameters:

$n(r)=\frac{N(r)}{N\left(r_{0}\right)} \quad x=\left(\frac{r}{r_{0}}\right)^{2} \quad q=\frac{T\left(r_{0}\right)}{T(r)}$

posing $\beta_{\mathrm{m}}\left(r_{0}\right)=\beta_{\mathrm{m}}^{0}$, and using Eq. (8), Eq. (9) takes the form:

$\beta_{\mathrm{a}}(r)=n(r) \cdot x \cdot q \cdot \beta_{\mathrm{m}}^{0} \cdot R_{0}-\beta_{\mathrm{m}}(r)$.

After rearranging the usual error propagation formula and neglecting covariances between the measured quantities, and the uncertainty on the altitude $x$, we get to:

$$
\begin{aligned}
\left(\frac{\delta \beta_{\mathrm{a}}}{\beta_{\mathrm{a}}}\right)^{2} & =\left(\frac{\beta_{\mathrm{m}} \cdot R}{\beta_{\mathrm{a}}}\right)^{2} \cdot\left[\left(\frac{\delta n}{n}\right)^{2}+\left(\frac{\delta q}{q}\right)^{2}\right. \\
& \left.+\left(\frac{\delta \beta_{\mathrm{m}}^{0}}{\beta_{\mathrm{m}}^{0}}\right)^{2}+\left(\frac{\delta R_{0}}{R_{0}}\right)^{2}+\frac{1}{R^{2}} \cdot\left(\frac{\delta \beta_{\mathrm{m}}}{\beta_{\mathrm{m}}}\right)^{2}\right] .
\end{aligned}
$$

Showing how the errors in the aerosol backscatter coefficient retrieval come from the signal measured, the estimation of transmission and density, and on the assumed value for the backscatter ratio at the calibration altitude.

We now discuss and quantify the individual contributions to be applied to our system. $\left(\frac{\delta n}{n}\right)$ is the uncertainty on the measured signal: it has a fixed contribution due to the statistics of photons arriving from the calibration altitude $r_{0}$, which we often place around $6-8 \mathrm{~km}$, and a contribution varying along the profile.

We detail the discussion for the two different modes of detection: if the signal is detected in photocounting mode, then $n$ is proportional to the sum of photoncounts arrived and detected during each series of consecutive time bins. The Poissonian statistics of photon arrival gives the standard deviation as the square root of the number of photoncounts. Each laser shot causes a burst of backscattered photons, and averaging $N$ of such bursts is a common way to increase the counting statistics, thus improving the signal to noise ratio 
by a factor $\sqrt{N}$. In our case, typical averaging times range from 5 to $60 \mathrm{~s}$, so that, given our laser pulse repetition rate, $N$ may range from 5000 to 60000 . As detailed before, photoncounting is performed over a series of 1024 consecutive time bins of adjustable width. In the measurements presented hereafter, the width of such bins was set to $200 \mathrm{~ns}$ (and consequently the vertical resolution of our profile to $30 \mathrm{~m}$, and its extent to $30 \mathrm{~km}$ ). If $b \mathrm{~kg}$ is the sky background photon count and $p$ is the overall photon count, the relative uncertainty on the lidar signal $n=p-b k g$ will be $\frac{\delta n}{n}=\frac{\delta p}{n}+\frac{\delta b k g}{n}$. Even in daylight, for our system, the sky background photoncounting rate is some $10^{6}$ photoncount $\mathrm{s}^{-1}$ and is negligible throughout a large part of the tropospheric return.

In current mode the waveform is digitized with an 8-bits analog to digital converter (ADC), and recorded. The digital resolution error, on the single sample, is equal to its least significant bit (LSB). On an average of $\mathrm{N}$ samples, as the LSB is dithered by noise from electronics and from inherent atmospheric variability, the averaged waveform resolution is increased by a factor $\sqrt{N}$ corresponding to an increment of $\frac{\log _{2} N}{2}$ bits. In our case, for $N=5000$, the averaged waveform has an equivalent LSB of 14 bits; for $N=60000$ the equivalent LSB is 16 bits. As above, if $b k g$ is the current caused by the sky background, or by any other electronic bias, and $p$ the overall current, $n=p-b k g$ and the relative uncertainty on the lidar signal will be $\frac{\delta n}{n}=\frac{\delta p}{n}+\frac{\delta b k g}{n}$. Practically, the digital uncertainty is usually much smaller than the one arising from the determination of $b \mathrm{~kg}$, computed as the average current level of the waveform in the 24 samples preceding the laser shot. Such current level is "noisy", due to electronics as well as inherent signal variability, so that the standard deviation $\mathrm{STD}_{b k g}$ of the sky background level is usually greater than the digital resolution error in every condition. Such standard deviation, taken as the uncertainty on the sky background signal, can be thought to affect equally every other portion of the current waveform, and so we put $\delta p=\delta b k g=\mathrm{STD}_{b k g}$.

$\frac{\delta q}{q}$ is the error on the transmission due to both molecular and aerosol extinction. The molecular extinction can be evaluated from the Rayleigh theory once the air density profile is obtained from measurements or from a suitable atmospheric model, while in absence of an independent measurement, $\beta_{\mathrm{a}}$ can be calculated from Eq. (11) only if a priori assumptions are made on the relation between aerosol extinction and backscatter coefficients (the so-called lidar ratio). In such assumptions lie the largest source of inaccuracy in lidar retrievals. We followed the standard Klett approach (Klett, 1981) and chose to fix the lidar ratio to piecewise constant values in regions where clouds or aerosols are present. Such regions are automatically identified by iteratively inspecting the values of backscatter ratio, depolarization ratio and altitude during the data processing, and recursively adjusting the lidar ratio accordingly. For instance, when thin liquid or ice clouds are identified in a given altitude range, the lidar ratio there is set to values known from literature (Chen et al., 2002; O'Connor et al., 2004). The lidar ratio for aerosol may easily range from $30-50 \mathrm{sr}$ in the case of dust (Mattis et al., 2002; Immler et al., 2003) to $80 \mathrm{sr}$ for biomass burning aerosol (Wandinger et al., 2002; Weinzierl et al., 2011), and reported values for volcanic ashes are in the range 45$60 \mathrm{sr}$ (Ansmann et al., 2010; Gross et al., 2011). Although our data process allows to constrain the aerosol lidar ratio value when additional aerosol optical depth measurements from sunphotometers are available (as in the San Pietro Capofiume station) (Marenco et al., 1997), or to provide an altitude dependent aerosol lidar ratio when the nitrogen Raman signal (Ansmann et al., 1990) is available during the nighttime, these opportunities were not attainable during the flight tests. Hence a constant aerosol lidar ratio was set to 50 sr everywhere, except when cirrus ( $30 \mathrm{sr}$ ) or thin water clouds (19 sr) were identified. To give an estimation of the uncertainty induced by such choice, following the literature (Russell et al., 1979; Bockmann et al., 2004) we write

$\left(\frac{\delta q}{q}\right)^{2}=4 \cdot\left(\delta \tau_{\mathrm{a}}^{2}+\delta \tau_{\mathrm{m}}^{2}\right) \cong 4 \cdot\left(\left(0.5 \cdot \tau_{\mathrm{a}}\right)^{2}+\left(0.1 \cdot \tau_{\mathrm{m}}\right)^{2}\right)$

where $\tau_{\mathrm{a}, \mathrm{m}}$ indicate the optical depths due to particulates and molecules, respectively.

$\frac{\delta \beta_{\mathrm{m}}^{0}}{\beta_{\mathrm{m}}^{0}}$ and $\frac{\delta \beta_{\mathrm{m}}}{\beta_{\mathrm{m}}}$ both reflect uncertainties on the molecular density, derived from other independent measurements or a suitable atmospheric model. In our case we put both of them equal to 0.01 .

$\frac{\delta R_{0}}{R_{0}}$ is the uncertainty on the $R\left(r_{0}\right)$ calibration value used in the retrieval; in our case, it is often possible to reach in a measurement session the upper part of the troposphere where the molecular scattering dominates. A conservative estimation is to put the uncertainty on $R_{0}$ at 0.02 .

\subsubsection{Volume and aerosol depolarization}

Depolarization measurements allow discrimination of various kind of aerosol and clouds (Sassen, 1991; di Sarra et al., 2001; Iwasaka et al., 2003; Wiegner et al., 2009). The volume linear depolarization ratio $\delta$ is defined as the ratio of the aerosol and molecular backscatter coefficients as

$\delta(r)=\frac{\beta_{\mathrm{m}}^{\text {cros }}(r)+\beta_{\mathrm{a}}^{\text {cros }}(r)}{\beta_{\mathrm{m}}^{\mathrm{par}}(r)+\beta_{\mathrm{a}}^{\mathrm{par}}(r)}$

where the superscript par and cros refer to backscattering with polarization parallel and perpendicular to the polarization of the emitted light. It can be directly expressed in terms of the ratio of the cross to the parallel-polarized lidar return signals, once the atmospheric return is split according to its polarization diversity and separately detected:

$\delta(r)=K \cdot \frac{n^{\text {cross }}(r)}{n^{\operatorname{par}}(r)}$. 
In Eq. (15) it is apparent that, apart from the coefficient $K$, a calibration constant accounting for the difference in the responses of the two channels, only the measured signals contribute to its random error. However, an incorrect determination of $K$ leads to significant systematic errors severely affecting the accuracy of the measurements. This coefficient can be directly measured by a variety of procedures (Freudenthaler et al., 2009; Alvarez et al., 2006) that exploit a controlled splitting of the backscattered light into its parallel and cross polarized components, to be fed into the receiving channels. In the data presented hereafter, a different depolarization calibration approach has been used, namely the $0^{\circ}$ calibration (Freudenthaler et al., 2009). In this approach $K$ is chosen in order for the depolarization to obtain the theoretical value to be expected for the atmospheric backscattering from a region where the aerosol presence can be considered negligible, and the observed depolarization is assumed to come from molecules alone (Young, 1980). In our case, this theoretical value was set to 0.014 (Behrendt et al., 2002). To determine $K$, a mean atmospheric profile with reduced SNR was created by averaging the measurements for several minutes, and an atmospheric region, namely the Rayleigh range, where particulate scattering could be considered negligible was determined around $8 \mathrm{~km}$. This procedure offers itself to criticism, as even a small amount of depolarizing aerosol in the Rayleigh range leads to an uncorrected bias, inducing a severe underestimation of the aerosol depolarization throughout the profile. An absolute determination of the $K$ coefficient of our system was performed after the flights, by illuminating the lidar telescope, covered with a thick slab of Teflon, with a collimated beam from a high power quartz lamp. The diffuse transmission in the forward direction, resulted in being completely unpolarized, allowed an absolute determination of the channel gain ratio. The agreement of the absolute determination of the $K$ coefficient with the value retrieved with the Rayleigh range approach confirmed the correctness of our previous assumptions. Another important source of systematic errors in depolarization measurements comes from the incomplete separation of parallel and cross polarized lidar returns, which leads to a mixing or a "cross talk" between receiving channels, again leading to underestimate the depolarization of aerosols. The cross talk can be taken into account and different methods have been envisaged to properly assess it (Biele et al., 2000; Reichardt et al., 2003); in our case we estimated the cross talk following the approach outlined in Snels et al. (2009) and the volume depolarization profiles are corrected accordingly (Cairo et al., 1999) for a cross talk of $2.5 \%$ between channels. This level of incomplete splitting in polarization is in good accordance with what directly tested in our optic laboratory on the polarization beamsplitter cube used in our system.

A second depolarization parameter, the particle depolarization (Cairo et al., 1999), is an intensive quantity widely used to classify aerosols. It can be retrieved by separately assessing the aerosol backscatter coefficient from cross and parallel backscattering, and then ratioing the two. The value of its uncertainty strongly depends on the amount of depolarizing aerosol present. We will discuss its uncertainties when presenting the measurement from one of our flights.

\section{Performances during flight}

The lidar system has been deployed in four flight tests on a C27-J Spartan of the italian Aeronautica Militare, all of them in daylight conditions. The system was placed in the aircraft, pointing to the zenith through an open hatch on the ceiling of the fuselage. In the first flight the system was not operative, and was subjected to intense mechanical stresses to verify the solidity of installation and to control the maintenance of the optical alignment after the flight. In the subsequent sections, data from the flights when the system was operative are presented and discussed.

\subsection{December 2010}

The system was equipped with an ancillary computer dedicated to store the data acquired from the avionics sensors of the C27-J (geo-reference, time, aircraft altitude, atmospheric dynamical and thermodynamical parameters, acquired at $1 \mathrm{~Hz}$ ) that were then used to interpret the lidar data. The parameters of the acquisition were set at $15 \mathrm{~m}$ vertical resolution for the current mode and $30 \mathrm{~m}$ vertical resolution for the photoncounting mode, the profiles extending respectively for $15 \mathrm{~km}$ and $30 \mathrm{~km}$. The flashlamp laser power was set to $90 \%$ of its maximum value. The integration time for each profile was set to $5 \mathrm{~s}$. The aircraft took off from the Aeronautica Militare military base of Pratica di Mare $\left(40.66^{\circ} \mathrm{N}, 12.48^{\circ} \mathrm{E}, 89 \mathrm{~m}\right.$ a.s.l.) and headed south to fly over the CNR-IMAA CIAO atmospheric observatory of Potenza $\left(40.60^{\circ} \mathrm{N}, 15.72^{\circ} \mathrm{E}, 760 \mathrm{~m}\right.$ a.s.l.) (Madonna et al., 2011) to obtain simultaneous measurements with a ground based reference system of proven accuracy (Mona et al., 2009). Unfortunately, low cloudiness above the station did not allow to operate the ground based system. However, RAMNI collected data throughout the flight, that was performed at a constant altitude of $2150 \mathrm{~m}$. The flight altitude was dictated by the fact that the aircraft flew unpressurized. The data obtained allowed us to assess the system performances, even in absence of a ground based comparison. Here, only data from the $532 \mathrm{~nm}$ channels will be discusses, since the $1064 \mathrm{~nm}$ channel was affected by a noise that prevented a quantitative determination of the backscattering at this wavelength. The source of this noise was not found in the timeframe of the project. However, the $1064 \mathrm{~nm}$ data, for this as well as the other flights, qualitatively confirmed the $532 \mathrm{~nm}$ observations.

Figure 2 shows the color coded profiles of the total backscattering coefficient (aerosol + molecular) and Fig. 3 shows the volume depolarization, measured during the flight. 


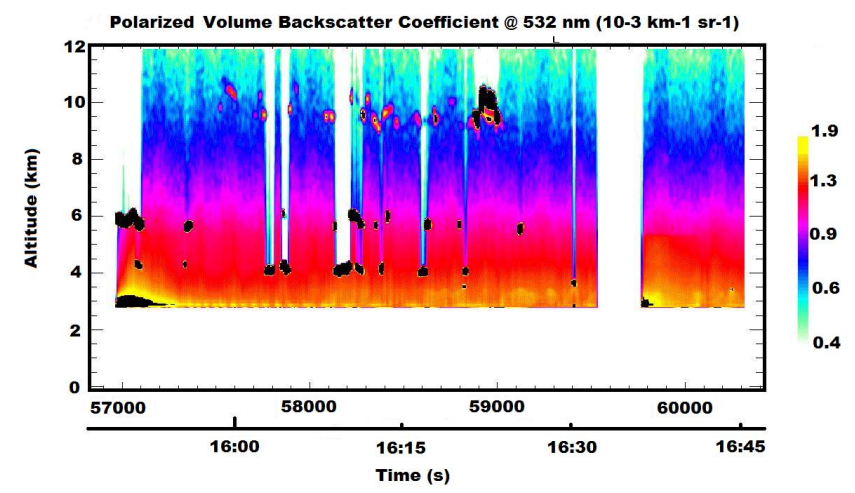

Fig. 2. Time vs. altitude curtain of the volume (aerosol + molecular) polarized backscattering coefficient, for the flight on 9 December 2010 .

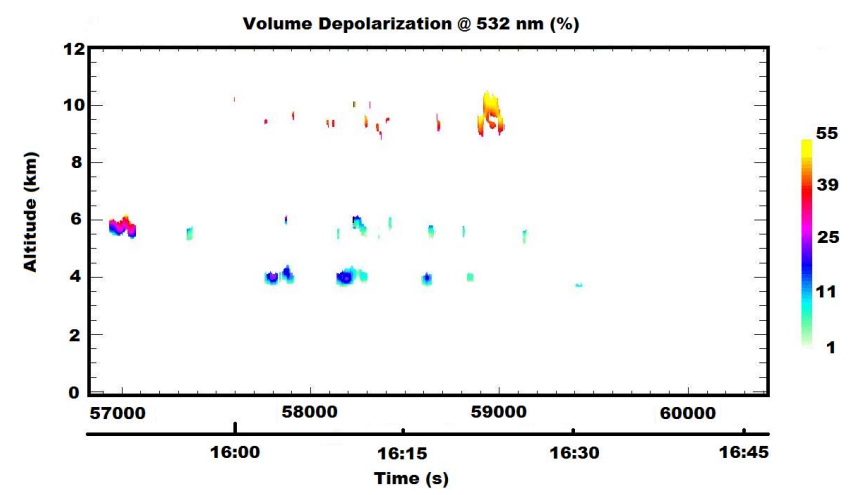

Fig. 3. Time vs. altitude curtain of volume depolarization ratio, for the flight on 9 December 2010.

Each profile represent an average over $60 \mathrm{~s}$. Noticeable is the presence of scattered clouds at $4 \mathrm{~km}$ and $6 \mathrm{~km}$ altitude (the black areas where data are outside the color scale), some of them optically so thick to inhibit the signal detection beyond them (at $57000 \mathrm{~s}, 57800 \mathrm{~s}, 58200 \mathrm{~s}, 58600 \mathrm{~s}$ ). The low value of the depolarization suggests a liquid or mixed phase for them. Other high-altitude ice clouds, discernible from the high values of depolarization associated with them, are present around $10 \mathrm{~km}$. The data collected during this flight, which we take as representative of a nearly aerosol free atmosphere, have been used to evaluate the sensitivity of the system when flying in daylight conditions, the most burdensome, by using the results of the uncertainty analysis reported in Sect. 3. The uncertainty to be attributed to the measurements of the volume backscattering coefficient and depolarization is shown in the upper panel of Fig. 4, (black line for depolarization, red line for backscattering), function of the distance from the aircraft. While the backscattering can be measured with reasonable sensitivity throughout the range, errors on depolarization measurements exceed $100 \%$ already a few kms from the system, forcing us to much longer integration times for calibration.

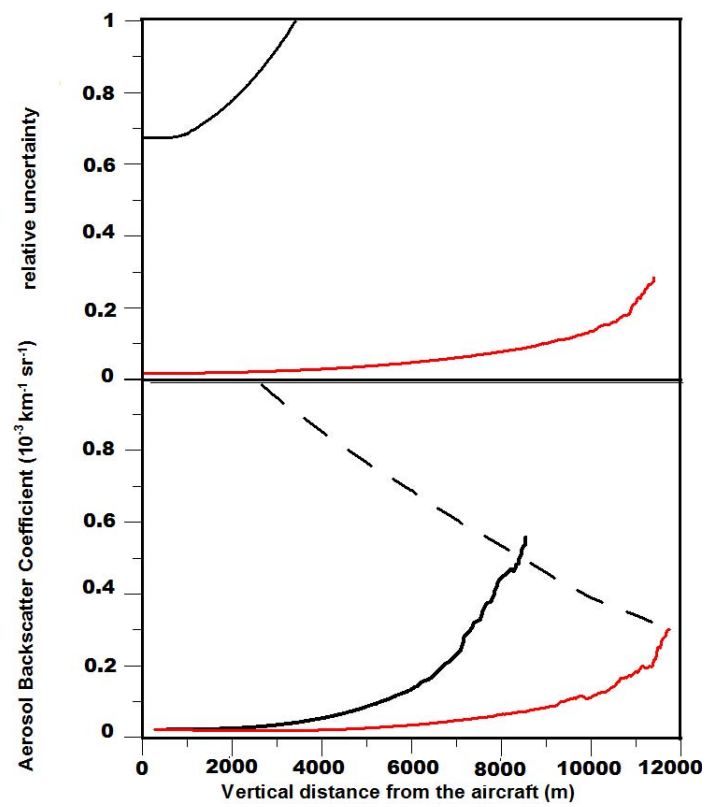

Fig. 4. Top panel: relative uncertainty for volume polarized backscattering coefficient (red line) and volume depolarization (black line) ratio. Bottom panel: curves of threshold aerosol backscattering coefficient, defined as the one giving $100 \%$ uncertainty, function of the distance from the aircraft (black solid line for $5 \mathrm{~s}$ integration time, red solid line for $60 \mathrm{~s}$ integration time). The dashed line represent the molecular backscattering coefficient values, and is reported for comparison. These curves were computed from the data from the first flight of RAMNI, when the aircraft was flying at $2150 \mathrm{~m}$ altitude.

The lower panel of Fig. 4 shows the threshold value of $\beta_{\mathrm{a}}(r)$ for an accurate determination. That is, considering the aerosol distributed uniformly along the vertical from the lidar to the vertical range $r$, the value that would be affected by a $100 \%$ uncertainty at $r$, given the characteristics and performances of the lidar system, the random measurement error, the uncertainties on aerosol extinction and on the determination of air density and calibration values. This aerosol threshold quantity depends on the distance from the lidar, and on the measurement integration time. It would also depend on the flight altitude, that we held fixed in our sensitivity and accuracy analysis, at the aircraft flight level $(2150 \mathrm{~m})$.

The two solid curves display such threshold value for different integration times (black one for $5 \mathrm{~s}$ integration time, red one for $60 \mathrm{~s}$ integration time). Considering an aircraft speed of about $400 \mathrm{~km} \mathrm{~h}^{-1}$, those integration times allow horizontal resolutions of respectively $0.5 \mathrm{~km}$ and $3 \mathrm{~km}$ along the line of flight. Also reported for comparison are the values of the molecular backscatter coefficient (dashed line), computed from temperature and pressure measured by an atmospheric sounding at Pratica di Mare. As instance, at $8000 \mathrm{~m}$ from the aircraft, for an integration time of $5 \mathrm{~s}$, the $100 \%$ uncertainty on the aerosol backscatter coefficient is reached at a 


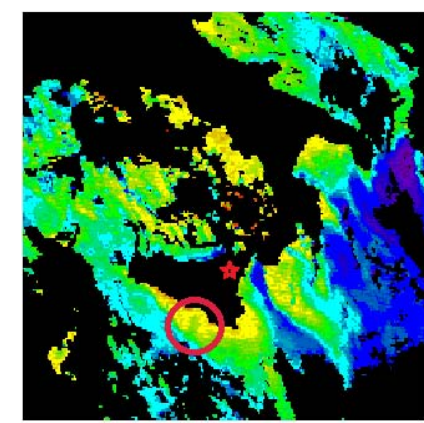

Angstrom coefficient

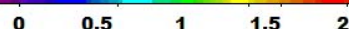

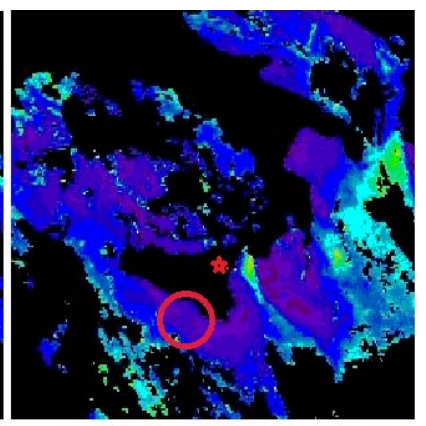

Aerosol Optical Thickness at $869 \mathrm{~nm}$

\section{0}

0.1

Fig. 5. Color coded aerosol optical thickness (right panel) and (531$869 \mathrm{~nm}$ ) Angström coefficient (left panel) by MODIS Terra, on 14 December 2010 at 12:10 UT. The circles highlight where an enhancement of optical thickness and a variation of the Angström coefficient with respect to its background values can be discerned, originated by the volcanic plume from Etna. The star show the position of the volcano.

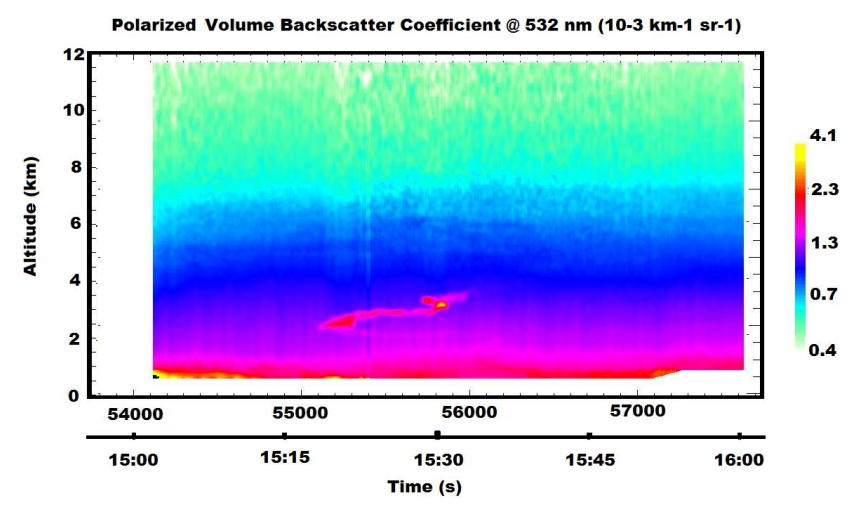

Fig. 6. Time vs. altitude curtain of parallel volume backscattering coefficient, for the flight on 14 January 2011.

value of $0.5 \times 10^{-3} \mathrm{~km}^{-1} \mathrm{sr}^{-1}$, i.e. for a total backscatter ratio of 2 at $10 \mathrm{~km}$ altitude (provided the aircraft flying altitude is $2150 \mathrm{~m}$ ); for an integration time of $60 \mathrm{~s}$, the same uncertainty is obtained for an aerosol backscatter coefficient of approximately $0.05 \times 10^{-3} \mathrm{~km}^{-1} \mathrm{sr}^{-1}$, i.e. for a total backscatter ratio of 1.1 at $10 \mathrm{~km}$ altitude.

It should be emphasized that this threshold aerosol value is higher than the minimum detectable aerosol signal. In fact in our error analysis, the conservative and relatively large value of the uncertainty induced by the arbitrary choice of the aerosol extinction plays a big role. Moreover, the uncertainty it causes on the determination of the aerosol coefficient at range $r$, depends on the vertical aerosol distribution from the lidar to $r$. In our computation, we posed ourselves in the unfavorable - and probably unlikely - condition of an aerosol uniformly distributed throughout that range.

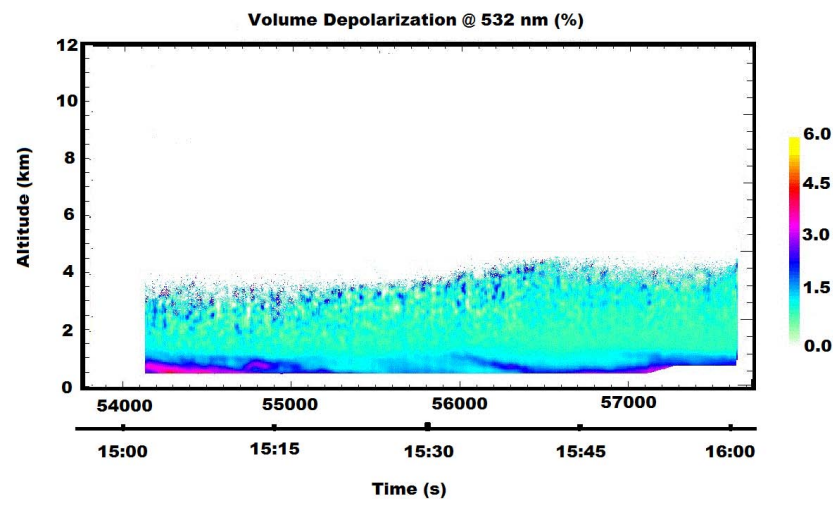

Fig. 7. Time vs. altitude curtain of volume depolarization ratio, for the flight on 14 January 2011.

\subsection{January 2011}

The third flight aimed at monitoring the volcanic plume originated from a brief eruptive episode of the Etna volcano $\left(37.73^{\circ} \mathrm{N}, 15.00^{\circ} \mathrm{E}, 3329 \mathrm{~m}\right.$ a.s.1.). The Etna started on 12 January a strombolian activity with explosive outbursts of pasty lava ejected a few tens or hundreds of meters into the air, the activity becoming stronger during the night. On the 14 , there was no activity responsible for lava emissions as in the previous day, and during our flight the volcano had already finished erupting since a few hours and only a plume persisted from the mouth of the volcano, pushed south south-westward by the prevailing winds. Figure 5 shows the aerosol optical depth (right panel) and Angström coefficient (left panel) as measured by MODIS-Terra at 12:10 UT on the 14. The circle highlights the region where the plume originated from the volcano was sought and detected during the flight. The volcanic plume is hardly discernible in the optical depth image, a little more so in the Angström coefficient image where a zone of reduced values can be noticed, spreading from the south-western part of the coast of Sicily, toward the Strait of Sicily, advected by the wind that blew almost perpendicular to the coastline.

The C27J took off from Pratica di Mare in the early afternoon and headed southward, making a transept parallel to the southwest sicilian coastline flying over the Strait of Sicily, at an altitude of about $1000 \mathrm{~m}$, a few tens of kilometers from the land. The aircraft passed below the plume originating from the volcano which was situated at an altitude of about 2-3000 m. The plume was detected approximately $150 \mathrm{~km}$ downwind from the source, and was subvisible. The plane flew at a minimum distance of about $1000 \mathrm{~m}$ from the base of the plume, that was considered to be a safe distance. Figures 6 and 7 show the color coded time series of profiles of total backscatter coefficient and depolarization - this latter extending only up to $4 \mathrm{~km}$ of altitude, because of high sky background - measured during the flight. Each profile represent an average over $60 \mathrm{~s}$. The data clearly shows the 


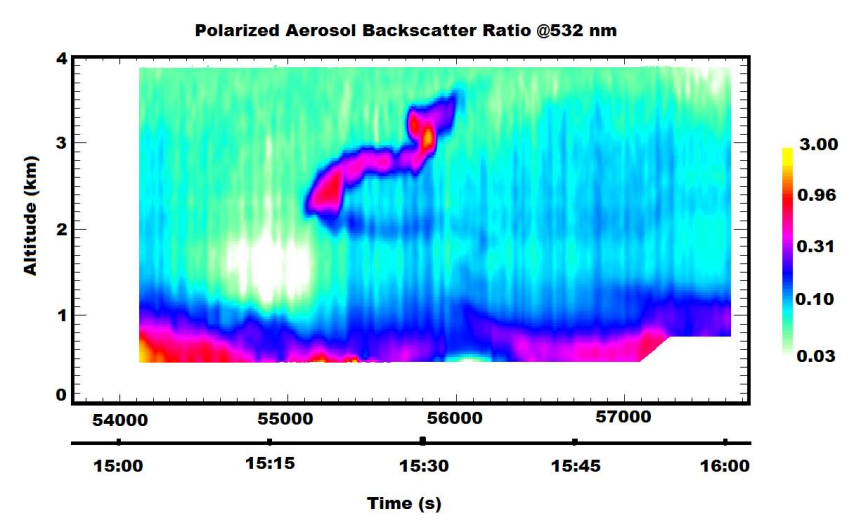

Fig. 8. Time vs. altitude curtain of the aerosol backscatter ratio, for the flight on 14 January 2011.

presence of a layered structure of particulates that extends between 2 and $3.5 \mathrm{~km}$, visible between 55000-56000 s. The origin of this structure was easily traced back to emissions from Etna, by inspecting the analysis of high altitude winds. The lack of any relevant depolarization in the backscattered light suggests that the particles were essentially liquid, probably sulfate particles condensed from water vapor and minor gases emitted from Etna, with no detectable presence of ash particles. Lidar observations for a similar event, performed in 2002 from the lidar station in Potenza, also reported the dominant presence of submicron sulfate particles (Villani et al., 2006). A zoom on the volcanic plume is reported in Fig. 8, where the aerosol backscatter ratio is presented. There, clearly discernible is the presence of low level aerosol extending to $1000-1500 \mathrm{~m}$, likely influenced by the transport off the coast, the noticeable presence of free tropospheric aerosols up to $4 \mathrm{~km}$, the elongated structure of the plume, with backscatter ratio as high as 4 in its higher portion, and a region of very clean air, apparent as a white spot at $1-2 \mathrm{~km}$ at $55000 \mathrm{~s}$.

On its way back along the south-east coast of the island, the plane flew close to Mount Etna and the pilot took pictures of the plume originating from its mouth, as displayed in Fig. 9.

\subsection{May 2011}

The flight was motivated by the forecast of the VAAC MetOffice announcing the presence of volcanic aerosol over the Po valley, above $11 \mathrm{~km}$ altitude and with concentrations ranging between 200 and $2000 \mu \mathrm{g} \mathrm{m}^{-3}$, as a result of the transport of the plume originated from the ongoing eruption of the Icelandic volcano Grimsvötn $\left(63.98^{\circ} \mathrm{N}, 19.70^{\circ} \mathrm{W}\right.$, $1725 \mathrm{~m}$ a.s.1.). The presence of the ash cloud was forecasted to occur between 06:00 UTC and 12:00 UTC. The C27J tookoff from Pratica di Mare at 08:03 LT (06:03 UTC). The aircraft followed a route toward the western end of the Po Valley, at an altitude of $1800 \mathrm{~m}$, which was considered safe for

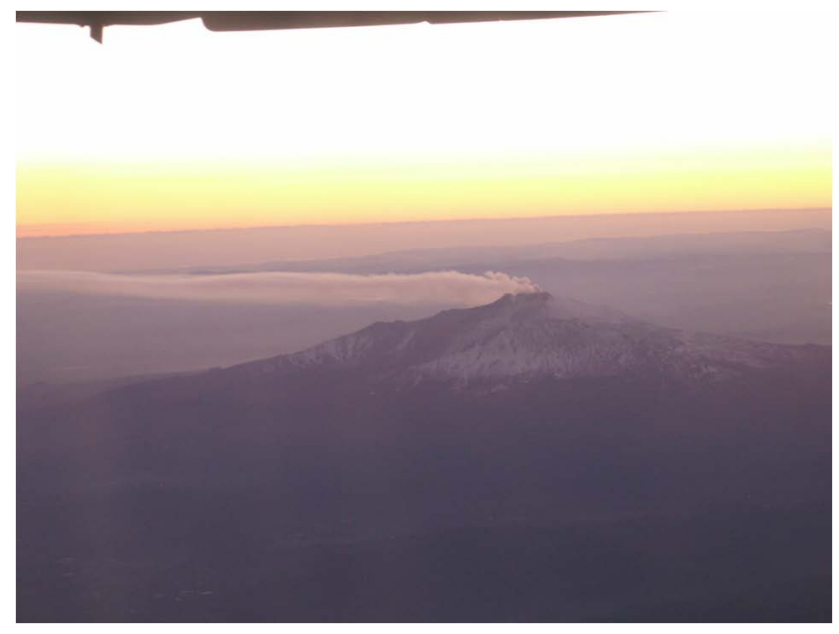

Fig. 9. A picture of mount Etna taken on 14 January 2010 from onboard the C27J-Spartan aircraft (courtesy T. Col. F. Palazzi).

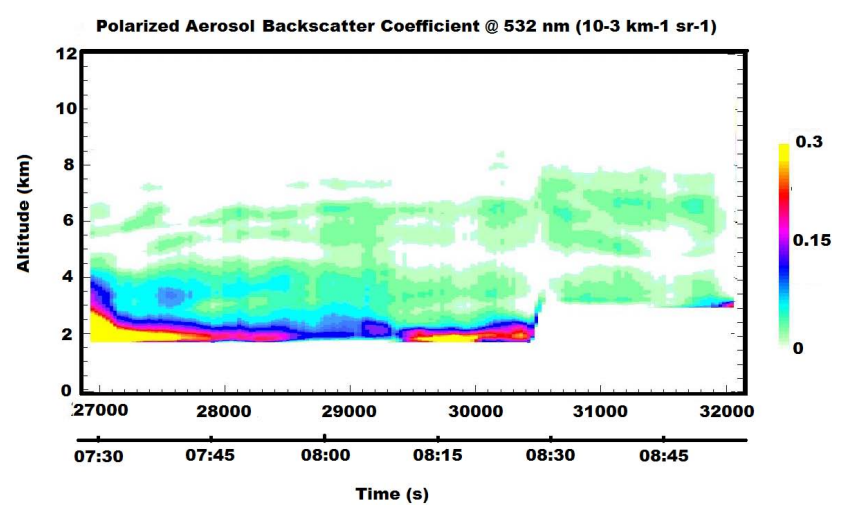

Fig. 10. Time vs. altitude curtain of aerosol backscattering coefficient, for the flight on 28 May 2011.

flight, and began taking measurements at 07:29 UTC, after an eastward turn, following the course of the river Po until it reached the Adriatic coast. There, it climbed to $3200 \mathrm{~m}$ at 08:30 UTC, and turned south-southeast continuing the flight along the Adriatic coastline. The measurements continued until the aircraft reached Ancona, then were shut off. The aircraft then came back to Pratica di Mare where it landed after about 4 flight hours.

The altitude of the supposed ash presence, and the order of magnitude of the aerosol backscatter coefficients to be expected, ranging from 2 to $20 \times 10^{-3} \mathrm{~km}^{-1} \mathrm{sr}^{-1}$, producing a lower limit for the aerosol backscatter ratio of 5 at $12 \mathrm{~km}$, posed this mission within the limit of our detection capabilities. Figures 10 and 11 report the color coded profiles of the total backscattering coefficient and volume depolarization. The data collected show the presence of layers of tropospheric aerosol from the flight level up to to about $7 \mathrm{~km}$, with values ranging from 0.1 to $0.3 \times 10^{-3} \mathrm{~km}^{-1} \mathrm{sr}^{-1}$. These layers show a maximum volume depolarization of $2-3 \%$ at 
Table A1. Values of the MPE for direct eye exposure to laser radiation, according to Sicherheitstechnischen Festlegungen und Anlagen für Lasergerate, VDE 1998 Beuth-Verlag, ISSN 0178-224X (Stachlewska et al., 2010).

\begin{tabular}{llll}
\hline & Criterion 1 & Criterion 2 & Criterion 3 \\
\hline Emission duration & $10^{-9}-10^{-7} \mathrm{~s}$ & $10^{-9}-10^{-7} \mathrm{~s}$ & $10^{-3}-10 \mathrm{~s}$ \\
Wavelength $315-400 \mathrm{~nm}$ & $5.6 \times t^{0.25} \times 10^{3} \mathrm{Jm}^{-2}$ & $5.6 \times t^{0.25} \times 10^{3} \mathrm{Jm}^{-2}$ & - \\
Wavelength 400-550 nm & $5 \times 10^{-3} \mathrm{Jm}^{-2}$ & $18 \times t^{0.75} \mathrm{Jm}^{-2}$ & $N^{-0.25} \times 5 \times 10^{-3} \mathrm{Jm}^{-2}$ \\
Wavelength 1050-1150 nm & $5 \times 10^{-2} \mathrm{Jm}^{-2}$ & $90 \times t^{0.75} \mathrm{Jm}^{-2}$ & $N^{-0.25} \times 5 \times 10^{-2} \mathrm{Jm}^{-2}$ \\
\hline
\end{tabular}

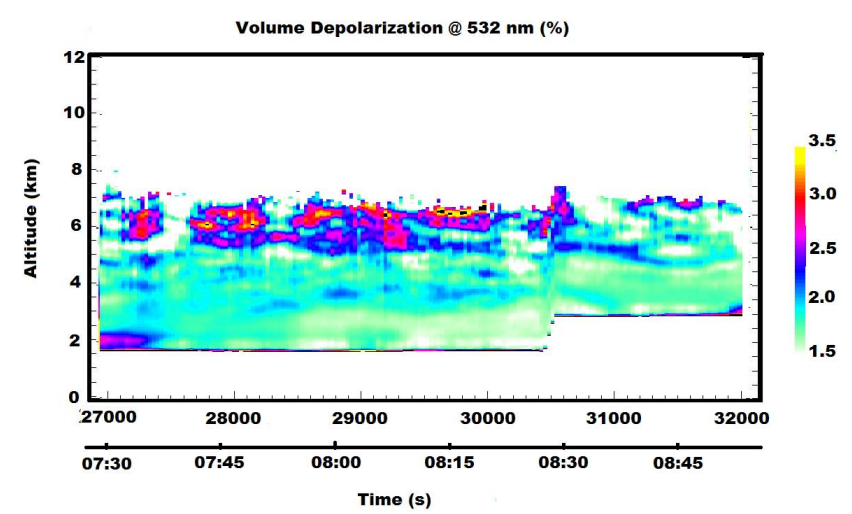

Fig. 11. Time vs. altitude curtain of volume depolarization ratio, for the flight on 28 May 2011.

around 6-7 km, which decreases downward. Above this layered structure, the aerosol is significantly reduced. An average particulate depolarization of $40-50 \%$ throughout the layer could be inferred. The uncertainty on the particulate depolarization is severely affected by the extremely low value of the aerosol backscattering, hence in our case, the error to attribute to this parameter exceeds $100 \%$. The inferred value would be consistent with what is expected for mineral dust, but a 5-days back trajectory analysis shows no sign of origin from dust source regions, hence does not support such attribution. In any case, the measurement uncertainty due to the paucity of aerosol does not allow a reliable classification.

Above $9 \mathrm{~km}$, no presence of aerosols was detected, with backscatter coefficient values within or above the $0.2 \times 10^{-3} \mathrm{~km}^{-1} \mathrm{sr}^{-1}$ lower limit indicated by the VAAC forecast. This lack of aerosol presence received an indirect confirmation by lidar data from a CALIPSO satellite overpass (not shown), that crossed our aircraft trajectory at 12:36 UTC, and reported no aerosol presence.

\section{Conclusions}

An airborne lidar was prepared and tested as a tool for monitoring the presence and estimate the mass density of particulate in the atmosphere. Three test flight have been performed, under conditions of high sky brightness. In one case, a volcanic plume originated from Etna volcano was detected, and presence of ash was excluded. In a different case, the system was able to exclude the presence of ash that was forecasted at concentrations considered hazardous to air traffic. The system has thus been tested under a variety of conditions and delivered information useful for managing civil contingencies, and for research on volcanic emissions. An improvement of the system performances is foreseen, in order to exploit the $1064 \mathrm{~nm}$ elastic channel, that may provide additional information on particle mean sizes. However, while the availability of airborne lidars as the one here presented, and the effort to improve the accuracy of its aerosol parameter retrieval is undoubtedly worth of the endeavour, no improvement will probably ever result - alone - in a totally unambiguous classification of the aerosol, and a quantitative assessment of the aerosol mass concentration through extinction-to-mass or backscatter-to-mass coefficients. The depolarizing properties of volcanic clouds - and its mass-to-backscatter ratio depend on the particular volcano, on the particular eruption, on the age of the ash cloud, on the thermodynamical conditions encountered along its trajectory, etc., the microphysics of volcanic clouds being largely unknown, and there is still a relatively poor database of in-situ and remote sensing measurements and comparisons to support the results of lidar inversions. The unequivocal attribution of the type of particles observed and a reliable estimate of their mass concentration will have to be based on ancillary information from transport models, and from the synergic use of other remote sensing (Gasteiger et al., 2011; Ansmann et al., 2010) and in-situ measurements (Flentje et al., 2010).

\section{Appendix A}

\section{Eye safety concerns}

The value of the maximum permissible exposure (MPE) for a pulsed laser radiation depends on various parameters such as the emitted wavelength, the pulse repetition frequency $(F)$, the duration of single pulse $(t)$, the total duration of the pulse train $(T)$, and the total exposure time $\left(T_{\max }\right)$. There are three separate criteria to be fulfilled, namely:

1. The MPE/pulse is limited by its value for each single pulse (single pulse limit). 
Table A2. Maximum permittible exposure for our system.

\begin{tabular}{llll}
\hline & $532 \mathrm{~nm}$ & $1064 \mathrm{~nm}$ & tot \\
\hline $\mathrm{MPE}_{1}$ & $5 \times 10^{-3} \mathrm{Jm}^{-2}$ & $50 \times 10^{-3} \mathrm{Jm}^{-2}$ & $55 \times 10^{-3} \mathrm{Jm}^{-2}$ \\
$\mathrm{MPE}_{2}$ & $6.4 \times 10^{-3} \mathrm{Jm}^{-2}$ & $31.8 \times 10^{-3} \mathrm{Jm}^{-2}$ & $38.2 \times 10^{-3} \mathrm{Jm}^{-2}$ \\
$\mathrm{MPE}_{3}$ & $1.25 \times 10^{-3} \mathrm{Jm}^{-2}$ & $12.5 \times 10^{-3} \mathrm{Jm}^{-2}$ & $13.75 \times 10^{-3} \mathrm{Jm}^{-2}$ \\
\hline
\end{tabular}

2. The MPE/pulse is limited by its value for all exposure times between $T$ and $T_{\max }$, divided by the number of pulses $N$ during this time period (average power limit).

3. The MPE/pulse is limited by its value for a single pulse, multiplied by $N-1 / 4$ where $N$ the number of pulses that occur over time $T_{\max }$ (repetitive pulse limit).

and the enforced MPE is the lowest among those identified by these criteria.

Let $T_{\max }=0.25 \mathrm{~s}$ be the time to close the eyes dazzled by a casual exposure to visible laser radiation (blink effect time). For a repetition frequency of $1 \mathrm{kHz}$, this physiological response time of the human eye to dazzling light gives $N=250$. In Table A1, the MPE limits in the enforced legislation are reported. If the emission takes place simultaneously on more wavelengths, the MPE is additive.

In Table A2 the maximum allowable values for our system are reported. The most compelling criterion appears to be the third. Using Eq. (1), the safety condition for the eyes (eye safety) is verified for $r \geq 1500 \mathrm{~m}$.

Acknowledgements. The authors express their sincere thanks to Gerardo De Canio, Alessandro Zambotti and the staff of the Laboratory of Qualification of Materials, Components and Systems of ENEA for the great willingness to collaborate in the project; to the Department of Earth and Environment of the National Research Council for financial support; to Gelsomina Pappalardo and the staff at CNR-IMAA for their availability to validate the system and for useful discussions on the interpretation of the data, and finally, to the italian Aeronautica Militare, and in particular the Reparto Sperimentale Volo, for uninterrupted support, contribution and great professionalism displayed in bringing to a successful end the system deployment in a short time.

Edited by: V. Amiridis

\section{References}

Alvarez, J. M., Vaughan, M. A., Hostetler, C. A., Hunt, W. H., Winker, D. M.: Calibration technique for polarization-sensitive lidars, J. Atmos. Ocean. Tech., 23, 683-699, 2006.

Ansmann, A., Riebesell, M., and Weitkamp, C.: Measurement of atmospheric aerosol extinction profiles with a Raman lidar, Opt. Lett., 15, 746-748, 1990

Ansmann, A., Tesche, M., Groß, S., Freudenthaler, Seifert, V. P., Hiebsch, A., Schmidt, J., Wandinger, U., Mattis, I., Müller, D., and Wiegner, M.: The 16 April 2010 major volcanic ash plume over central Europe: EARLINET lidar and AERONET photometer observations at Leipzig and Munich, Germany, Geophys. Res. Lett., 37, L13810, doi:10.1029/2010GL043809, 2010.

Ansmann, A., Tesche, M., Seifert, P., Groß, S., Freudenthaler, V., Apituley, A., Wilson, K. M., Serikov, I., Linné, H., Heinold, B., Hiebsch, A., Schnell, F., Schmidt, J., Mattis, I., Wandinger, U., and Wiegner, M.: Ash and fine-mode particle mass profiles from EARLINET-AERONET observations over central Europe after the eruptions of the Eyjafjallajökull volcano in 2010, J. Geophys. Res., 116, D00U02, doi:10.1029/2010JD015567, 2011.

Behrendt, A. and Nakamura, T. : Calculation of the calibration constant of polarization lidar and its dependency on atmospheric temperature, Optics Exp., 10, 805-817, 2002.

Biavati, G., Di Donfrancesco, G., Cairo, F., and Feist, D. G.: Correction scheme for close-range lidar returns, Appl. Optics, 50, 5872-5882, 2011.

Biele, J., Beyerle, G., and Baumgarten, G.: Polarization lidar: corrections of instrumental effects, Optics Exp., 7, 427-435, 2000.

Böckmann, C., Wandinger, U., Ansmann, A., Bösenberg, J., Amiridis, V., Boselli, A., Delaval, A., De Tomasi, F., Frioud, M., Grigorov, I. V., Hågård, A., Horvat, M., Iarlori, M., Komguem, L., Kreipl, S., Glarchevêque, G., Matthias, V., Papayannis, A., Pappalardo, G., Rocadenbosch, F., Rodrigues, J. A., Schneider, J., Shcherbakov, V., and Wiegner, M.: Aerosol Lidar Intercomparison in the Framework of the EARLINET Project, 2. Aerosol Backscatter Algorithms, Appl. Optics, 43, 977-989, 2004.

Browell, E. V., Butler, C. V., Ismail, S., Robinette, P. A., Carter, A. F., Higdon, N. S., Toon, O. B., Schoeberl, M. R., and Tuck, A. F.: Airborne lidar observations in the wintertime arctic stratospherePolar stratospheric Clouds, Geophys. Res. Lett., 17, 385-388, doi:10.1029/GL017i004p00385, 1990.

Bukowiecki, N., Zieger, P., Weingartner, E., Jurányi, Z., Gysel, M., Neininger, B., Schneider, B., Hueglin, C., Ulrich, A., Wichser, A., Henne, S., Brunner, D., Kaegi, R., Schwikowski, M., Tobler, L., Wienhold, F. G., Engel, I., Buchmann, B., Peter, T., and Baltensperger, U.: Ground-based and airborne in-situ measurements of the Eyjafjallajökull volcanic aerosol plume in Switzerland in spring 2010, Atmos. Chem. Phys., 11, 10011-10030, doi:10.5194/acp-11-10011-2011, 2011.

Cairo, F., Congeduti, F., Poli, M., Centurioni, S., and Di Donfrancesco, G.: A survey of signal-induced noise in photomultiplier detection of wide dynamics luminous signals, Rev. Sci. Instrum., 67, 3274-3280, doi:10.1063/1.1147408, 1996.

Cairo, F., Di Donfrancesco, G., Adriani, A., Pulvirenti, L., and Fierli, F.: Comparison of Various Linear Depolarization Parameters Measured by Lidar, Appl. Optics, 38, 4425-4432,1999.

Cavalieri, O., Cairo, F., Fierli, F., Di Donfrancesco, G., Snels, M., Viterbini, M., Cardillo, F., Chatenet, B., Formenti, P., Marticorena, B., and Rajot, J. L.: Variability of aerosol vertical distribution in the Sahel, Atmos. Chem. Phys., 10, 12005-12023, doi:10.5194/acp-10-12005-2010, 2010.

Cavalieri, O., Di Donfrancesco, G., Cairo, F., Fierli, F., Snels, M., Viterbini, M., Cardillo, F., Chatenet, B., Formenti, P., Marticorena, B., and Rajot, J. L.: The AMMA MULID network for aerosol characterization in West Africa, Int. J. Remote Sens., 32, 5485-5504, doi:10.1080/01431161.2010.502156, 2011.

Chazette, P., Sanak, J., and Dulac, F.: New Approach for Aerosol Profiling with a Lidar Onboard an Ultralight Aircraft: Application to the African Monsoon Multidisciplinary Analysis, 
Environ. Sci. Technol., 41, 8335-8341, doi:0.1021/es070343y, 2007.

Chen, W. N., Chiang, C. W., and Nee, J. B.: The lidar ratio and depolarization ratio for cirrus clouds, Appl. Optics, 41, 64706497, 2002.

Di Liberto, L., Angelini, F., Pietroni, I., Cairo, F., DiDonfrancesco, G., Viola, A., Argentini, S., Fierli, F., Gobbi, G., Maturilli, M., Neuber, R., and Snels, M.,: Estimate of the Arctic Convective Boundary Layer Height from Lidar Observatons: A Case Study, Ad. Met., 1-9, 851927, doi:10.1155/2012/851927, 2012.

di Sarra, A., Di Iorio, T., Cacciani, M., Fiocco, G., and Fua, D.: Saharan dust profiles measured by lidar from Lampedusa, J. Geophys. Res., 106, 10335-10347, 2001.

Donovan, D. P., Whiteway, J. A., and Carswell, A. I.: Correction for nonlinear photon-counting effects in lidar systems, Appl. Optics, 32, 6742-6753, 1993.

Flamant, C., Pelon, J., Chazette, P., Trouillet, V., Quinn, P., Frouin, R., Bruneau, D., Leon, J.-F., Bates, T., Johnson, J., and Livingstone, T.: Airborne lidar measurements of aerosol spatial distribution and optical properties over the Atlantic Ocean during a European pollution outbreak of ACE-2, Tellus B, 52, 662-677, 2000.

Flentje, H., Claude, H., Elste, T., Gilge, S., Köhler, U., PlassDülmer, C., Steinbrecht, W., Thomas, W., Werner, A., and Fricke, W.: The Eyjafjallajökull eruption in April 2010 - detection of volcanic plume using in-situ measurements, ozone sondes and lidar-ceilometer profiles, Atmos. Chem. Phys., 10, 10085-10092, doi:10.5194/acp-10-10085-2010, 2010.

Freudenthaler, V., Esselborn, M., Wiegner, M., Heese, B., Tesche, M., Ansmann, A., Müller, D., Althausen, D., Wirth, M., Fix, A., Ehret, G., Knippertz, P., Toledano, C., Gasteiger, J., Garhammer, M., and Seefeldner, M. : Depolarization ratio profiling at several wavelengths in pure Saharan dust during SAMUM 2006, Tellus B, 61, 165-179, 2009.

Gasteiger, J., Groß, S., Freudenthaler, V., and Wiegner, M.: Volcanic ash from Iceland over Munich: mass concentration retrieved from ground-based remote sensing measurements, Atmos. Chem. Phys., 11, 2209-2223, doi:10.5194/acp-11-22092011, 2011.

Gross, S., Freudenthaler, V., Wiegner, M., Gasteiger, J., Geiss, A., and Schnell, F.: Dual-wavelength linear depolarization ratio of volcanic aerosols: lidar measurements of the Eyjafjallajokull plume over Maisach, Germany, Atmos. Environ., 48, 8596, 2011.

Immler, F. and Schrems, O.: Vertical profiles, optical and microphysical properties of Saharan dust layers determined by a ship-borne lidar, Atmos. Chem. Phys., 3, 1353-1364, doi:10.5194/acp-3-1353-2003, 2003.

Iwasaka, Y., Shibata, T., Nagatani, T., Shi, G.-Y., Kim, Y. S., Matsuki, A., Trochkine, D., Zhang, D., Yamada, M., Nagatani, M., Nakata, H., Shen, Z., Li, G., Chen, B., and Kawahiraand, K.: Large depolarization ratio of free tropospheric aerosols over the Taklamakan desert revealed by lidar measurements: possible diffusion and transport of dust particles, J. Geophys. Res., 108, 8652, doi:10.1029/2002JD003267, 2003.

Klett, J. D.: Stable analytical inversion solution for processing lidar returns, Appl. Optics, 20, 211-220, 1981.
Lilley, M., Lovejoy, S., Strawbridge, K., and Schertzer, D.: 23/9 dimensional anisotropic scaling of passive admixtures using lidar data of aerosols, Phys. Rev. E, 70, 036307, doi:10.1103/PhysRevE.70.036307, 2004.

Madonna, F., Amodeo, A., Boselli, A., Cornacchia, C., Cuomo, V., D’Amico, G., Giunta, A., Mona, L., and Pappalardo, G.: CIAO: the CNR-IMAA advanced observatory for atmospheric research, Atmos. Meas. Tech., 4, 1191-1208, doi:10.5194/amt4-1191-2011, 2011.

Marenco, F., Santacesaria, S., Bais, A. F., Balis, D., di Sarra, A., Papayannis, A., and Zerefos, C.: Optical properties of tropospheric aerosols determined by lidar and spectrophotometric measurements (Photochemical Activity and Solar Ultraviolet Radiation campaign), Appl. Optics, 36, 6875-6886, 1997.

Marenco, F., Johnson, B., Turnbull, K., Newman, S., Haywood, J., Webster, H., and Ricketts, H.: Airborne lidar observations of the 2010 Eyjafjallajokull volcanic ash plume, J. Geophys. Res., 116, D00U05, doi:10.1029/2011JD016396, 2011.

Mattis, I., Ansmann, A., Muller, D., Wandinger, U., and Althausen, D.: Dual wavelength Raman lidar observations of the extinctionto backscatter ratio of Saharan dust, Geophys. Res. Lett., 29, 1306, doi:10.1029/2002GL014721, 2002.

McGill, M. J., Hlavka, D. L., Hart, W. D., Spinhirne, J. D., Scott, V. S., and Schmid, B.: The Cloud Physics Lidar: Instrument description and initial measurement results, Appl. Optics, 41, 37253734, 2002.

Moerl, P., Reinhardt, M. E., Renger, W., and Schellhase, R.: The use of the airborne lidar ALEX-F for aerosol tracing in the lower troposphere, Contr. Atmas. Phys., 45, 403-410, 1981.

Mona, L., Pappalardo, G., Amodeo, A., D’Amico, G., Madonna, F., Boselli, A., Giunta, A., Russo, F., and Cuomo, V.: One year of CNR-IMAA multi-wavelength Raman lidar measurements in coincidence with CALIPSO overpasses: Level 1 products comparison, Atmos. Chem. Phys., 9, 7213-7228, doi:10.5194/acp-97213-2009, 2009.

O'Connor, E. J., Illingworth, A. J., and Hogan, R. J.: A technique for autocalibration of cloud lidar, J. Atmos. Ocean. Tech., 21, 777-786, 2004.

Petersen, G. N.: A short meteorological overview of the Eyjafjallajokull eruption 14 April-23 May 2010, Weather, 65, 203-207, 2010.

Reichardt, J., Baumgart, R., and McGee, T. J.: Three signal method for accurate measurements of depolarization ratio with lidar, Appl. Optics, 42, 4909-4913, 2003.

Renger, W., Kiemle, C., Schreiber, H. G., Wirth, M., and Morl, P.: Correlative measurements in support of LITE using the airborne backscatter lidar ALEX, in: Advances in Atmospheric Remote Sensing with Lidar, edited by: Ansmann, A., Neuber, R., Rairoux, P., and Wandinger, U., Springer-Verlag, Berlin, 165$168,1997$.

Russell, P. B., Swissler, T. J., and McCormick, M. P.: Methodology for error analysis and simulation of lidar aerosol measurements, Appl. Optics, 18, 3783-3797, 1979.

Sassen, K.: The polarization lidar technique for cloud research: a review and current assessment, B. Am. Meteorol. Soc., 72, 18481866, 1991. 
Schumann, U., Weinzierl, B., Reitebuch, O., Schlager, H., Minikin, A., Forster, C., Baumann, R., Sailer, T., Graf, K., Mannstein, H., Voigt, C., Rahm, S., Simmet, R., Scheibe, M., Lichtenstern, M., Stock, P., Rüba, H., Schäuble, D., Tafferner, A., Rautenhaus, M., Gerz, T., Ziereis, H., Krautstrunk, M., Mallaun, C., Gayet, J.F., Lieke, K., Kandler, K., Ebert, M., Weinbruch, S., Stohl, A., Gasteiger, J., Groß, S., Freudenthaler, V., Wiegner, M., Ansmann, A., Tesche, M., Olafsson, H., and Sturm, K.: Airborne observations of the Eyjafjalla volcano ash cloud over Europe during air space closure in April and May 2010, Atmos. Chem. Phys., 11, 2245-2279, doi:10.5194/acp-11-2245-2011, 2011.

Snels, M., Cairo, F., Colao, F., and Di Donfrancesco, G.: Calibration method for depolarization lidar measurements, Int. J. Remote Sens., 30, 5725-5736, doi:10.1080/01431160902729572, 2009.

Stachlewska, I. S., Neuber, R., Lampert, A., Ritter, C., and Wehrle, G.: AMALi - the Airborne Mobile Aerosol Lidar for Arctic research, Atmos. Chem. Phys., 10, 2947-2963, doi:10.5194/acp10-2947-2010, 2010.

Tull, R. G.: A comparison of Photon counting and Current Measuring techniques in Spectrometry of Faint Sources, Appl. Optics, 7, 2023-2029, 1968.

Villani, M. G., Mona, L., Maurizi, A., Pappalardo, G., Tiesi, A., Pandolfi, M., D'Isidoro, M., Cuomo, V., and Tampieri, F. : Transport of volcanic aerosol in the troposphere: The case study of the 2002 Etna plume, J. Geophys. Res., 111, D21102, doi:10.1029/2006JD007126, 2006.
Wandinger, U., Muller, D., Bockmann, C., Althausen, D., Matthias, V., Bosenberg, J., Weiss, V., Fiebig, M., Wendisch, M., Stolhl, A., and Aansmann, A.: Optical and microphysical characterization of biomass-burning and industrial-pollution aerosols from multi wavelength lidar and aircraft measurements, J. Geophys. Res., 107, 8125, doi:10.1029/2000JD000202, 2002.

Weinzierl, B., Sauer, D., Esselborn, M., Petzold, A., Veire, A., Rose, M., Mund, S., Wirth, M., Ansmann, A., Tesche, M., Gross, S., Freudenthaler, V.: Microphysical and optical properties of dust and tropical biomass burning aerosol layers in the Cape Verde region - an overview of the airborne in situ and lidar measurements during SAMUM-2, Tellus B, 63, 589-618, doi:10.1111/j.16000889.2011.00566.x, 2011.

Wiegner, M., Gasteiger, J., Kandler, K., Weinzierl, B., Rasp, K., Esselborn, M., Freudenthaler, V., Heese, B., Toledano, C., Tesche, M., and Althausen, D.: Numerical simulations of optical properties of Saharian dust aerosols with emphasis on lidar applications, Tellus B, 61, 180-194, 2009.

Wiegner, M., Gasteiger, J., Groß, S., and Schnell, F.: Characterization of the Eyjafjallajökull ash-plume: Potential of lidar remote sensing, J. Phys. Chem. Earth, 45-46, 79-86, doi:10.1016/j.pce.2011.01.006, 2011.

Young, A. T.: Revised depolarization corrections for atmospheric extinction, Appl. Optics, 19, 3247-3248, 1980. 